\title{
Correction to: Dikes, rice, and fish: how rapid changes in land use and hydrology have transformed agriculture and subsistence living in the Mekong Delta
}

\author{
Van Kien Nguyen ${ }^{1,2}$ (D) Jamie Pittock ${ }^{1} \cdot$ Daniel Connell $^{3}$
}

Published online: 25 November 2019

(C) Springer-Verlag GmbH Germany, part of Springer Nature 2019

\section{Correction to: Regional Environmental Change (2019)} 19:2069-2077

https://doi.org/10.1007/s10113-019-01548-x

The article which was recently published contained a minor error in Figure 2a. The author incorrectly provided the image during production process. The correct figure is given in this article.

Figure 2a:

Publisher's note Springer Nature remains neutral with regard to jurisdictional claims in published maps and institutional affiliations.

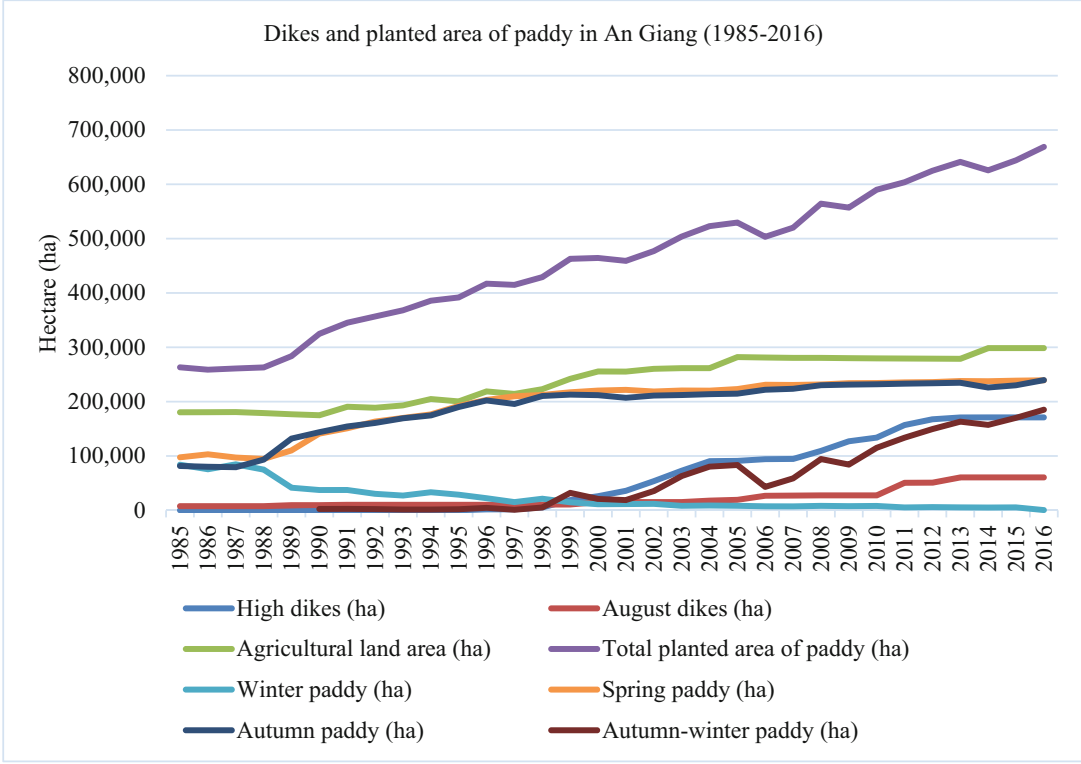

The online version of the original article can be found at https://oi.org/10. 1007/s10113-019-01548-x

Van Kien Nguyen

nv.kien@anu.edu.au; nvkien@agu.edu.vn

Jamie Pittock

Jamie.Pittock@anu.edu.au

Daniel Connell

Daniel.connell@anu.edu.au
Fenner School of Environment and Society, The Australian National University, 48 LinnaeusWay, Acton ACT, Canberra 2600, Australia

2 Research Center for Rural Development, An Giang University, 18 Ung Van Khiem St., Long Xuyen City, An Giang Province, Vietnam

3 Environment and Development Program, Crawford School of Public Policy, ANU College of Asia \& the Pacific, The Australian National University, Acton ACT, Canberra 2600, Australia 